\title{
Surgical Techniques Used for the Treatment of Atrial Fibrillation
}

\author{
Jason O. Robertson, MD; Christopher P. Lawrance, MD; \\ Hersh S. Maniar, MD; Ralph J. Damiano Jr, MD
}

\begin{abstract}
The use of surgical lesion sets for the treatment of atrial fibrillation has been increasing, particularly in patients with complicated anatomical substrates and those undergoing concomitant surgery. Preferences in terms of lesion set, surgical approach and ablation technology vary by center. This review discusses both the surgical techniques and the outcomes for the most commonly performed procedures in the context of recent consensus guidelines. The Cox-Maze IV, pulmonary vein isolation, extended left atrial lesion sets, the hybrid approach and ganglionated plexus ablation are each reviewed in an attempt to provide insight into current clinical practice and patient selection. $\quad$ (Circ J 2013; 77: 1941-1951)
\end{abstract}

Key Words: Ablation; Arrhythmia; Atrial fibrillation; Atrial flutter; Lesion sets

A trial fibrillation (AF) is the most common arrhythmia, affecting 7 million people worldwide. Due to increased awareness and an aging population, there has been a $66 \%$ increase in hospital admissions for AF over the past 20 years, and AF carries significant morbidity secondary to the negative hemodynamic effects caused by loss of atrial contraction, atrioventricular dyssynchrony and tachycardiainduced cardiomyopathy. Pharmacologic therapies aimed at the treatment of AF have historically been hindered by significant shortcomings, including limited efficacy and systemic toxicity. ${ }^{1}$ Moreover, prevention of the most feared complication of AF, embolic stroke, requires the use of warfarin for anticoagulation during rhythm or rate control therapy and carries with it a defined risk of major bleeding. Return of normal sinus rhythm (NSR) has several theoretical advantages over rate control therapy. These include restoration of atrial systolic function, which has a significant effect on both symptoms and cardiac output in some patients, particularly those with congestive heart failure; and cessation of anticoagulation, which eliminates the major risk of bleeding. Although rhythm control strategies have not been proven to be superior to rate control strategies, in part because of poor efficacy and side effects of the medications a follow-up analysis of the AFFIRM trial did show that the presence of NSR was associated with a mortality reduction of $47 \% .^{2}$ It is because of the inadequacies of medical management of AF that both catheter-based and surgical procedures aimed at restoring NSR have arisen.

Surgical intervention for AF is indicated in both patients with medically refractory lone AF and patients undergoing cardiac surgery for other pathology who have concomitant AF and would benefit from the procedure. The latter group comprises the majority of patients undergoing surgical ablation. In a review of our experience at Washington University from 1996 to 2005, the incidence of AF was $24 \%$ in patients referred for valvular procedures \pm coronary artery bypass grafting $(\mathrm{CABG})$. Recently, the role of surgery for AF was clarified and endorsed in the 2012 consensus statement released by the Heart Rhythm Society in partnership with the European Heart Rhythm Association, the European Cardiac Arrhythmia Society, the American College of Cardiology, the American Heart Association, and the Society of Thoracic Surgeons. Surgical ablation of AF is indicated for (1) all symptomatic AF patients undergoing other cardiac surgery; (2) selected asymptomatic AF patients undergoing cardiac surgery in which the ablation can be performed with minimal additional risk; and (3) symptomatic lone AF patients who prefer a surgical approach, have failed 1 or more attempts at catheter ablation, or are not candidates for catheter ablation. ${ }^{3}$ Relative indications for surgery at our institution are (1) AF patients at high risk for stroke, such as patients with persistent $\mathrm{AF}$ and a $\mathrm{CHADS}_{2}$ score $\geq 2$ who develop a contraindication to long-term anticoagulation, ${ }^{4}$ and (2) high-risk patients with persistent AF who have had previous cerebrovascular events occur while appropriately anticoagulated. Surgery is a complimentary approach to catheter ablation.

No one lesion set is universally applied to treat AF. The specific ablation technology used, the lesion sets created and results all vary widely from center to center. One shortcoming of comparing results in the existing literature is that many groups have had different standards for follow-up and outcome endpoints. Where possible, in this review, we focus on studies that are in accordance with consensus definitions for reporting outcomes in clinical trials of AF ablation. ${ }^{3}$ Specifically, 1-year success should be defined as freedom from AF,

Received June 5, 2013; accepted June 5, 2013; released online July 3, 2013

Division of Cardiothoracic Surgery, Washington University School of Medicine, Barnes-Jewish Hospital, St. Louis, MO, USA

Mailing address: Ralph J. Damiano Jr, MD, Division of Cardiothoracic Surgery, Washington University/Barnes-Jewish Hospital, 660 S.

Euclid Avenue, Campus Box 8234, St. Louis, MO 63110, USA. E-mail: damianor@wustl.edu

ISSN-1346-9843 doi:10.1253/circj.CJ-13-0721

All rights are reserved to the Japanese Circulation Society. For permissions, please e-mail: cj@j-circ.or.jp 
A

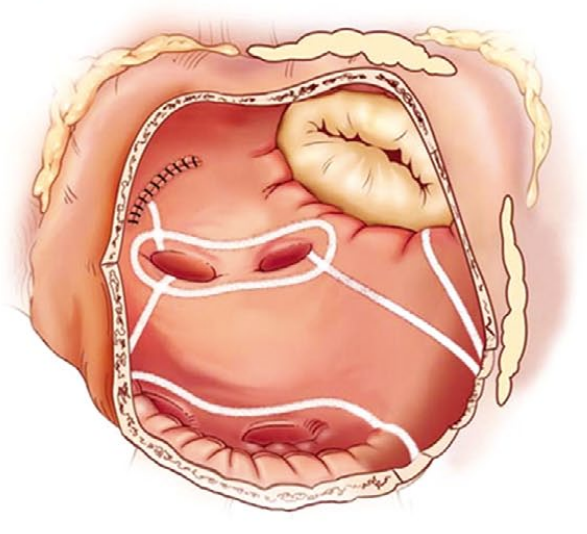

B

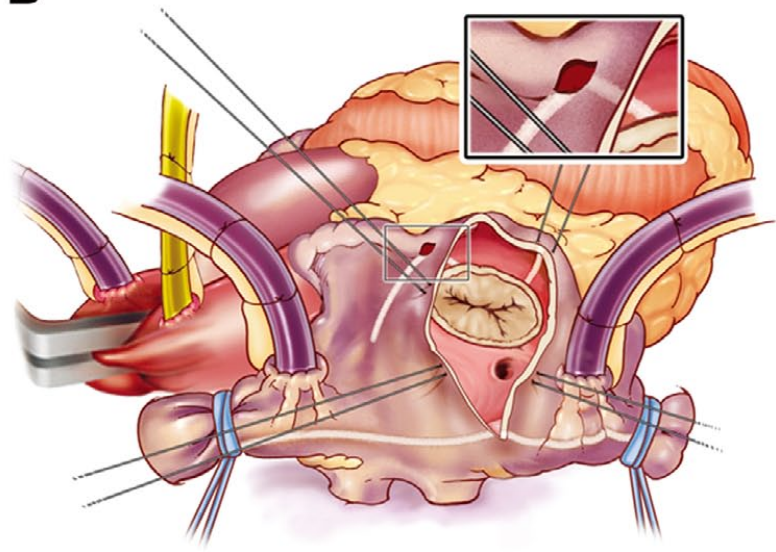

Figure 1. The Cox-Maze IV lesion set. (A) The left atrial lesion set comprises right and left pulmonary vein isolation, connecting lesions between the left and right superior and inferior pulmonary veins, a lesion from the left atrial appendage excision site to the pulmonary vein and a lesion to the mitral valve annulus. (B) The right atrial lesion set consists of lines of ablation along the superior and inferior venae cavae, the free wall of the right atrium and down to the tricuspid valve annulus. Adapted from reference 11 with permission.

atrial flutter (AFL) and atrial tachycardia (AT) while off class I or III antiarrhythmic drug (AAD) therapy, as assessed from the end of a 3-month blanking period to 12 months following the procedure. Recurrent AF should be defined as an atrial tachyarrhythmia (ATA) lasting at least 30s and documented by electrocardiography or other recording system; however, reporting standards for patients with implantable, continuousmonitoring systems have yet to be determined. Minimum follow-up screening includes (1) a 12-lead electrocardiogram at each follow-up visit, (2) 24-h Holter monitoring at 12-months, and (3) symptom-driven event monitoring. Patients with persistent AF (pAF) or longstanding pAF (LSP AF) should additionally have 24 -h Holter monitoring every 6 months. Attention to these accepted guidelines will allow surgeons to assess the effectiveness of different lesion sets in various patient populations and effectively advance the field.

\section{Overview of Historical Lesion Sets}

During the 1980 s, several groups began to develop surgical procedures to treat AF. These are notable only for historical significance because they failed to simultaneously address the 3 main sequelae of AF: (1) patient discomfort and anxiety from palpitations; (2) AV dyssynchrony, which compromises cardiac hemodynamics; and (3) increased risk of thromboembolic stroke from stasis of blood flow. Two of the first procedures were the left atrial (LA) isolation procedure and the corridor procedure. The LA isolation procedure, which was introduced by Williams et al, ${ }^{5}$ restored some patients to NSR but failed to reduce the risk of thromboembolism. The corridor procedure was introduced by Guiraudon's group in $1985^{6}$ and resulted in an isolated strip of atrial septum containing both the sinoatrial (SA) and atrioventricular (AV) nodes. Although this restored NSR, it failed to address the thromboembolic complications that resulted from the still fibrillatory atria. In 1985, Dr James Cox described an atrial transection procedure that consisted of a long incision across both atria into the septum. This procedure successfully cured AF in a canine model but was ineffective in humans. It was this procedure, however, that pro- vided the groundwork for the subsequent Cox-Maze procedure (CMP).

The first surgical AF procedure that was effective in humans was introduced by Cox in 1987 after extensive animal investigation. This procedure, now formally known as the CMP, utilized a biatrial "cut-and-sew" technique in an attempt to guide the native sinus impulse to both atria and the AV node while blocking all possible macroreentrant circuits. By restoring NSR and AV synchrony while maintaining atrial transport function, the CMP significantly reduced the risk of thromboembolism, stroke and hemodynamic compromise. ${ }^{7,8}$ Importantly, it was designed to provide a standardized approach that would be effective in all patients.

Unfortunately, the first version of the CMP was complicated by late chronotropic incompetence and a high rate of pacemaker implantation because of a incision through the "sinus tachycardia region" of the atrial pacemaker complex. ${ }^{9}$ To address the problem, the CMP underwent two further modifications, eventually resulting in the Cox-Maze III. This lesion set became the gold standard for the surgical treatment of AF. ${ }^{10}$ Despite its clinical success, however, the procedure was seldom performed, because of its technical complexity and prolonged time on cardiopulmonary bypass (CPB).

\section{The Cox-Maze IV}

\section{Surgical Technique}

To simplify the CMP, our group at Washington University replaced the majority of the "cut-and-sew" lesions that comprise CMP III with a combination of bipolar radiofrequency (RF) ablation and cryoablation in a procedure termed the CMP IV (Figure 1A,B). The CMP IV is performed through either a median sternotomy, often in combination with other cardiac procedures, or a less-invasive right minithoracotomy. All patients undergo routine transesophageal echocardiography (TEE) to rule out the presence of LA clot. If a patient is in AF at the time of surgery and clot has been excluded, the patient is electrically cardioverted following a bolus of amiodarone. Both the right and left pulmonary veins (PV) are bluntly dissected after 


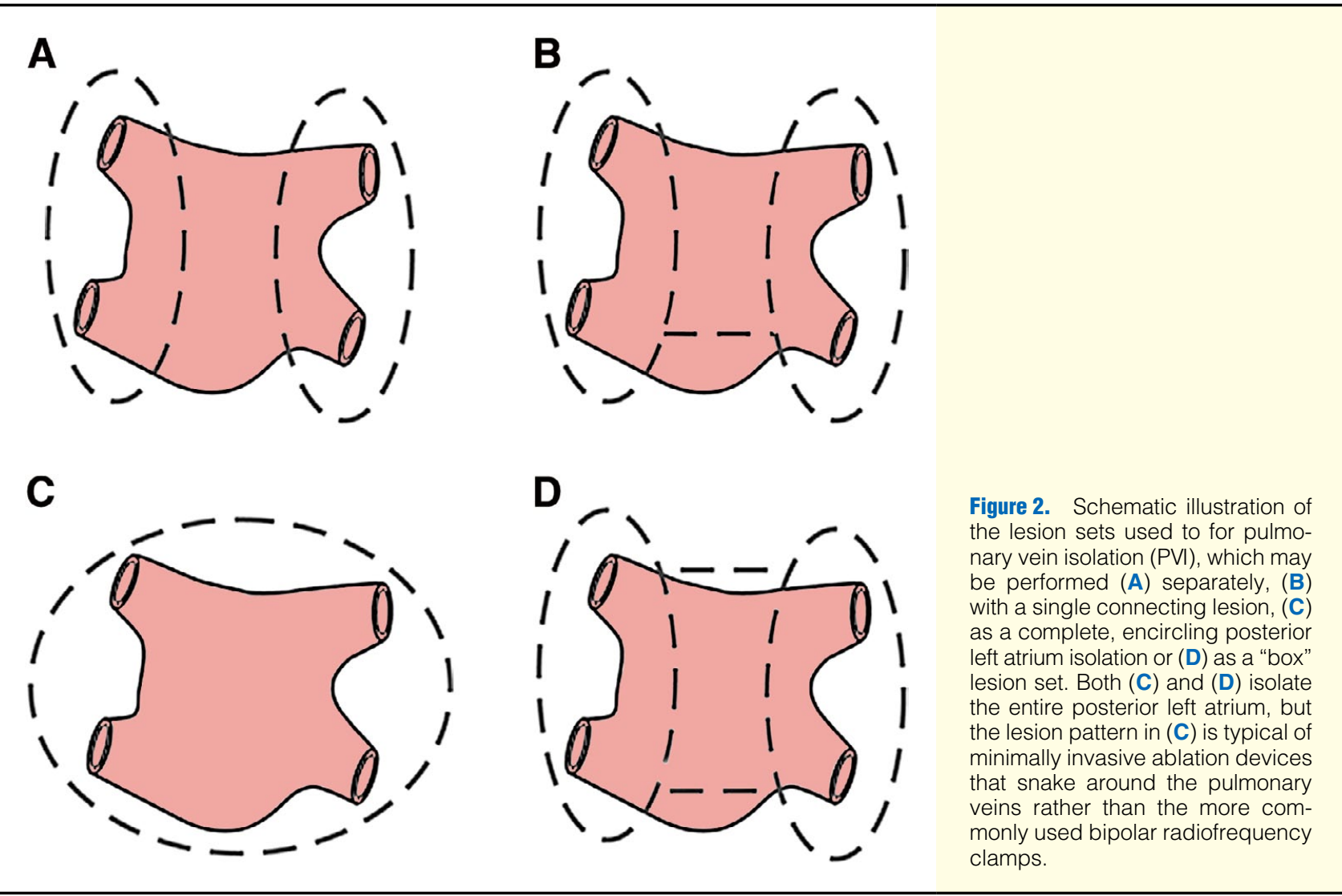

induction of $\mathrm{CPB}$ with the patient maintained at normothermia. Pacing thresholds are measured from each PV. The PVs are isolated using a bipolar RF clamp so that a ring of ablation surrounds a cuff of atrial tissue around the orifice of both the left and right PVs. Electrical isolation is then confirmed by documenting exit block from each PV when the operation is performed through a full sternotomy and from the right PVs only in patients that undergo a right minithoracotomy.

The patient is cooled to $34^{\circ} \mathrm{C}$, and the right atrial (RA) lesion set (Figure 1B) is performed on the beating heart while on CPB. A small purse-string suture that is wide enough to accommodate 1 jaw of the bipolar RF clamp is placed at the base of the RA appendage. Through this purse-string, an ablation line is created on the RA free wall towards the junction of the RA and superior vena cava (SVC). A vertical atriotomy is then made from just above the intraatrial septum to the AV groove near the free margin of the heart. This atriotomy should be at least $2 \mathrm{~cm}$ from the first free wall ablation. Through this atriotomy a bipolar RF clamp is used to create ablation lines up to the SVC and down to the inferior vena cava (IVC). Because cryoablation preserves the fibrous skeleton of the heart, it is ideal for ablation near valvular tissue. From the superior aspect of the incision, a 3-cm linear cryoprobe is used to create an endocardial ablation to the tricuspid valve at the 2 o'clock position. The cryoprobe is then placed through the purse-string at the base of the appendage and used to create a second endocardial cryoablation directed towards the tricuspid valve at the 10 o'clock position. In some patients, the atriotomy may be replaced with 2 additional purse-string sutures: 1 just above the intraatrial septum midway between the SVC and IVC and 1 just adjacent to the AV groove. This is the standard approach for patients having a right minithoracotomy.
The aorta is then cross-clamped and cold blood cardioplegia is administered. The left atrial lesion set (Figure 1A) is typically performed under cardioplegic arrest. First, the LA appendage (LAA) is amputated, and a bipolar RF clamp is used to create a line of ablation through this incision into the left inferior PV. The LAA is then excised, and a standard left atriotomy is performed. If needed, it can be extended superiorly onto the dome of the LA and inferiorly around the right inferior PV. In patients undergoing a right minithoracotomy, the LAA is oversewn from the endocardial surface following the atriotomy. A box lesion, which essentially isolates the entire posterior LA, is completed by connecting the atriotomy both inferiorly and superiorly to the ablation line encircling the left PVs using bipolar RF ablation (Figure 2). From the inferior portion of the atriotomy, the RF clamp is then used to create an ablation line across the floor of the LA down towards the mitral valve annulus. This ablation line should cross the coronary sinus, if possible, ideally in the space between the circumflex and right coronary arterial circulation. In the majority of patients who have a right dominant circulation, this is approximately adjacent to the P2 cusp of the posterior leaflet of the mitral valve. Because of the thickness of the AV groove in this area, cryoablation is used to bridge what is usually a $1-2 \mathrm{~cm}$ gap and connect this lesion to the mitral valve annulus. Finally, the coronary sinus is ablated in line with the isthmus lesion in order for it to be complete. This is done with epicardial cryoablation in order to ensure a full thickness ablation. Pacing wires should be left at the end of the procedure to manage postoperative bradycardia and arrhythmias.

\section{Surgical Results}

The CMP proved to have excellent long-term results. A series 


\begin{tabular}{|c|c|c|c|c|c|c|c|c|c|}
\hline \multirow[b]{2}{*}{ Author } & \multirow[b]{2}{*}{$\mathbf{n}$} & \multirow[b]{2}{*}{ Method and access } & \multirow{2}{*}{$\begin{array}{l}\text { Surgical } \\
\text { ablation } \\
\text { technology }\end{array}$} & \multicolumn{6}{|c|}{ Lesion set performed ${ }^{\star}$} \\
\hline & & & & $\begin{array}{l}\text { LAA } \\
\text { exclusion/ } \\
\text { excision }\end{array}$ & PVI & Box & GP & LOM & ALAL \\
\hline McClelland ${ }^{33}$ & 20 & $\begin{array}{l}\text { Bilateral thoracotomy/ } \\
\text { VATS }\end{array}$ & $\begin{array}{l}\text { Bipolar RF } \\
\text { clamp }\end{array}$ & $\mathrm{N}$ & Y & $\mathrm{N}$ & Y & $Y$ & $\mathrm{~N}$ \\
\hline Bagge $^{29}$ & 42 & Bilateral VATS & $\begin{array}{l}\text { Bipolar RF } \\
\text { clamp }\end{array}$ & $Y(32)$ & Y & $\mathrm{N}$ & Y & $Y(40)$ & $\mathrm{N}$ \\
\hline $\operatorname{Han}^{32}$ & 43 & Bilateral VATS & $\begin{array}{l}\text { Bipolar RF } \\
\text { clamp/pen }\end{array}$ & Y & Y & $\mathrm{N}$ & Y & Y & $\mathrm{N}$ \\
\hline Edgerton $^{31}$ & 52 & $\begin{array}{c}\text { Bilateral thoracotomy/ } \\
\text { VATS }\end{array}$ & $\begin{array}{l}\text { Bipolar RF } \\
\text { clamp }\end{array}$ & Y (44) & Y & $\mathrm{N}$ & Y & Y & $\mathrm{N}$ \\
\hline Wang ${ }^{34}$ & 81 & Bilateral VATS & $\begin{array}{l}\text { Bipolar RF } \\
\text { clamp }\end{array}$ & Y & Y & $\mathrm{N}$ & Y & $\mathrm{N}$ & $\mathrm{N}$ \\
\hline Boersma $^{30}$ & 61 & Bilateral VATS & $\begin{array}{l}\text { Bipolar RF } \\
\text { clamp/pen }\end{array}$ & $Y(60)$ & Y & $Y(10)^{* *}$ & $\mathrm{NS}^{\dagger}$ & $\mathrm{NS}^{\dagger}$ & $Y^{* *}$ \\
\hline
\end{tabular}

${ }^{*}(\mathrm{n})$ is specified when not all patients received a particular ablation line. ${ }^{* *}$ Additional lines could be made to the aortic trigone (10 patients), or a roof line (17 patients) could be created, all at the discretion of the surgeon. 'This varied by center. At 1 hospital, only right-sided GP were ablated and the LOM was cut. At another center, bilateral GP were ablated but the LOM was left alone. ALAL, additional left atrial lesions; Box, box lesion set; GP, ganglionated plexus; LAA, left atrial appendage; LOM, ligament of Marshall; PVI, pulmonary vein isolation; VATS, videoassisted thoracoscopic surgery; N, no; Y, yes; NS, specific number not specified.

of 187 patients from our institution undergoing a CMP III showed $97 \%$ freedom from symptomatic AF at 5.4 years, and results were similar for lone and concomitant procedures. ${ }^{10}$ Similarly, the CMP IV has demonstrated excellent long-term results for all patient subgroups. A recent prospective, singlecenter trial followed 100 consecutive patients undergoing a lone CMP IV between 2002 and 2010 at Washington University. The mean follow-up was $17 \pm 10$ months, and the study enrolled patients who had paroxysmal (PAF; 31\%), persistent (pAF; 6\%), and longstanding pAF (LSP AF; 63\%). The study showed postoperative freedom from AF to be $90 \%$ at both 12 and 24 months, and freedom from AF and AADs was $82 \%$ and $84 \%$, respectively, at these same time points. ${ }^{11}$ Similar results were seen in a separate study of 282 CMP IV patients, the majority of whom received concomitant cardiac surgery. In that group, the observed freedom from $\mathrm{AF}$ and AADs was $78 \%$ at 12 months despite an average LA diameter of $5.5 \pm 1.2 \mathrm{~cm}$ for concomitant surgery patients. ${ }^{12}$ The fact that more stringent consensus guideline endpoints were used in the CMP IV studies makes these data difficult to compare with prior CMP III results, ${ }^{3}$ but despite the variations in follow-up methodology, a separate propensity analysis has shown no significant difference in the freedom from AF between CMP III and IV patients. $^{13}$

The original iteration of the CMP IV lacked a complete box lesion surrounding the PVs, and the box lesion was only routinely performed for all patients beginning in 2005. Although there has been some concern that electrical and mechanical exclusion of the entire posterior RA would compromise atrial function, cardiac MRI has demonstrated that this is not the case. ${ }^{14}$ In fact, our group has shown that isolating the entire posterior LA by creating a "box" is preferable to isolating the left and right PVs separately, with or without a connecting lesion (Figure 2). ${ }^{11}$ In our study, 78 patients underwent a box lesion and were shown to have a higher freedom from $\mathrm{AF}(96 \%$ vs. $86 \%)$ and freedom from AF off AADs (79\% vs. $47 \%)$ at 1 year compared with patients who received the non-box lesion. ${ }^{11}$

Operative times have also been significantly reduced with the adoption of the CMP IV. Mean aortic cross-clamp times were significantly shorter for a lone CMP IV than for a lone CMP III (41 \pm 13 min vs. $93 \pm 34$ min, $\mathrm{P}<0.001) .{ }^{11}$ Mean con- comitant clamp times were also significantly decreased from $122 \pm 37$ min with the CMP III to $92 \pm 37$ min with the CMP IV $(\mathrm{P}<0.005) .{ }^{15}$ In addition, the major complication rate has decreased from $10 \%$ with the CMP III to $1 \%$ with the CMP IV. ${ }^{16}$ Thus, the replacement of surgical incisions with lines of ablation has decreased the morbidity and complexity of the procedure while maintaining similar success rates.

Risk factors for recurrence after 1 year include enlarged LA diameter, failure to create a box lesion, and early atrial tachyarrhythmias. Multiple groups, including our own, have confirmed the link between increasing atrial size and operative failure, ${ }^{12,17}$ and the probability of recurrence was found to exceed $50 \%$ when LA diameter was $>8 \mathrm{~cm} .{ }^{12}$ The onset of early atrial tachyarrhythmias is thought to be a marker of advanced atrial fibrosis causing a pathologic substrate. Outcomes may also be affected by surgeon-dependent factors, such as hasty or incorrect use of ablation technology or failure to properly perform certain lesions.

\section{PV Isolation (PVI)}

\section{Surgical Technique}

PVI is used to describe a variety of techniques that result in the electrical isolation of the PVs from the remainder of the LA. PVI can be performed with lesions encircling the right and left PVs individually, with or without an intervening connecting lesion, or as a box lesion isolating the entire posterior LA (Figure 2). Regardless of the lesion set used, PVI can be performed without $\mathrm{CPB}$, making it an attractive treatment option for patients with lone AF in whom the procedure can be done using a minimally invasive, thoracoscopic approach. Various energy sources have been used for PVI; however, many have difficulty creating reliable transmural lesions on the beating heart. ${ }^{18}$ Because of the shortcomings of unipolar devices, our institution has favored bipolar RF clamps for this procedure.

Before attempting an off-pump approach, intraoperative TEE is performed in order to evaluate whether there is LA thrombus. If a clot is identified, the procedure is either aborted or converted to a CPB procedure in order to minimize the risk of systemic thromboembolism. If no clot is identified, external defibrillator pads are placed, and the patient is positioned in the 
Table 2. Follow-up and Freedom From ATAs/AADs for Published PVI Series Reporting Results According to HRS/EHRA/ECAS Consensus Guidelines

\begin{tabular}{|c|c|c|c|c|c|c|c|c|}
\hline \multirow{2}{*}{ Author } & \multirow{2}{*}{$\mathbf{n}$} & \multirow{2}{*}{$\begin{array}{l}\text { Average LA } \\
\text { size }(\mathrm{cm})\end{array}$} & \multirow{2}{*}{$\begin{array}{l}\text { Follow-up } \\
\text { endpoint }\end{array}$} & \multirow{2}{*}{ Monitoring type } & \multicolumn{4}{|c|}{ Freedom from ATAs and AADs } \\
\hline & & & & & Overall & PAF & pAF & LSP AF \\
\hline McClelland ${ }^{33}$ & 20 & $4.2 \pm 0.3$ & 12 months & 30-day Holter & $\begin{array}{c}75 \% \\
(15 / 20)\end{array}$ & $\begin{array}{c}91 \% \\
(10 / 11)\end{array}$ & $\begin{array}{l}80 \% \\
(4 / 5)\end{array}$ & $\begin{array}{l}25 \% \\
(1 / 4)\end{array}$ \\
\hline Bagge $^{29}$ & 42 & $\begin{array}{l}\text { Median (range): } \\
4.5(2.6-6.2)\end{array}$ & 12 months & EKG/24- to 48-h Holter & $\begin{array}{c}52 \% \\
(17 / 33)\end{array}$ & NS & NS & NS \\
\hline $\operatorname{Han}^{32}$ & 45 & $4.3 \pm 0.6$ & 12 months & 30-day Holter & $\begin{array}{c}65 \% \\
(28 / 43)\end{array}$ & $\begin{array}{l}65 \% \\
(20 / 31)\end{array}$ & $\begin{array}{l}67 \% \\
(8 / 12)\end{array}$ & - \\
\hline Edgerton $^{31}$ & 52 & $\begin{array}{l}\text { Median (range): } \\
4.8(3.7-6.0)\end{array}$ & 12 months & $\begin{array}{l}\text { 24-h Holter or 2- to } \\
\text { 3-week event monitoring }\end{array}$ & $\begin{array}{c}73 \% \\
(38 / 52)\end{array}$ & $\begin{array}{c}73 \% \\
(38 / 52)\end{array}$ & - & - \\
\hline Wang ${ }^{34}$ & 81 & $5.3 \pm 1.1$ & 12 months & 24- to 48-h Holter & $\begin{array}{c}80 \% \\
(65 / 81)\end{array}$ & - & - & $\begin{array}{c}80 \% \\
(65 / 81)\end{array}$ \\
\hline Boersma $^{30}$ & 61 & $4.3 \pm 0.7$ & 12 months & 7-day Holter & $\begin{array}{c}66 \% \\
(40 / 61)\end{array}$ & $\begin{array}{c}69 \% \\
(31 / 45)\end{array}$ & $\begin{array}{c}56 \% \\
(9 / 16)\end{array}$ & - \\
\hline
\end{tabular}

*Unless AF had otherwise been documented by EKG or 24- or 48-h Holter. AADs, antiarrhythmic drugs; AF, atrial fibrillation; ATAs, atrial tachyarrhythmias; EKG, electrocardiogram; LA, left atrial; LSP AF, longstanding pAF; PAF, paroxysmal AF; pAF, persistent AF. Other abbreviations as in Table 1.

left lateral decubitus position with the right arm tucked at the side. A camera port is then placed in the 4 th intercostal space, approximately $2 \mathrm{~cm}$ anterior to the mid-axillary line, and additional working ports are placed in the 2 nd and 6 th intercostal spaces along the anterior axillary line.

The pericardium is opened anterior and parallel to the phrenic nerve, and blunt dissection is used to identify the space between the right superior PV and the right pulmonary artery. A specialized thoracoscopic dissector and guide sheath are introduced via the lower port. The device is advanced through the previously dissected space and articulated until the tip is between the right superior PV and the right pulmonary artery, at which time the dissector is removed, leaving only the guide sheath in place.

The patient is cardioverted into NSR at this time, and pacing thresholds are obtained from each PV in order to evaluate for conduction block at the conclusion of the procedure. A bipolar RF clamp is introduced and placed around the right PVs, where 2-3 consecutive ablations are performed. The clamp is moved slightly between each ablation in order to ablate as large a cuff of the LA as possible. Exit block from the right PVs is then confirmed by pacing. Further ablations are performed as needed until electrical isolation is confirmed.

The patient is then repositioned in the right lateral decubitus position. The procedure is duplicated on the left side, with minimal adjustments based on anatomy: the thoracoscopic port is placed slightly posterior to the mid-axillary line, and the pericardiotomy is performed parallel and posterior to the phrenic nerve in order to expose the left PVs. Prior to closing the chest, the LAA is occluded with either a stapler or an occluding device. ${ }^{19}$ Because of the significant risk of tears and bleeding posed by using an endoscopic stapler in this location, our group prefers to use clip devices. ${ }^{20}$

\section{Surgical Results}

Although PVI can be performed via a minimally invasive approach without the need for $\mathrm{CPB}$, the success of this technique has been variable and highly dependent on patient selection. Moreover, because surgeons have been performing thoracoscopic PVI for close to a decade, it is challenging to compare results of historical series with modern reports that utilize the consensus guidelines' follow-up definitions. ${ }^{3}$ Although numerous series are available in the literature, ${ }^{21-25}$ only 6 conform to modern standards (Tables 1,2). ${ }^{26-31}$ The smaller single-center studies $(n=20-52)$ report overall 1-year freedom from ATAs between $65 \%$ and $81 \%$, but success decreases to $51-75 \%$ when freedom from AADs is also considered (Table 2). ${ }^{26,28-30}$ Those studies are all comparable in terms of the lesion sets that were performed, with the notable exception that McClelland et $\mathrm{al}^{30}$ did not perform LAA exclusion/excision (Table 1). It is important to note that the majority of reported patients had PAF, and LA sizes were relatively small, with averages in the low to mid $4 \mathrm{~cm}$ range (Table 2). The largest single-center study enrolled 81 patients, all with LSP AF, and reported a high 1-year freedom from ATAs and AADs of $80 \%$ despite an average LA size of $5.3 \pm 1.1 \mathrm{~cm} .{ }^{31}$ The results of those studies are promising, though limited by their small sample sizes.

The type and duration of AF are known to affect the outcome of PVI and thus limit the utility of this approach. In a multicenter trial of 100 patients undergoing minimally invasive, bilateral PV isolation, autonomic denervation, and LAA resection, $87 \%$ were found to be free of AF or atrial flutter by Holter monitoring at a mean follow-up of $13.6 \pm 8.2$ months; ${ }^{21}$ however, those patients with longstanding pAF only had a $71 \%$ incidence of NSR at the conclusion of the study period compared with $93 \%$ of those with PAF, and AADs were only stopped in $62 \%$ of patients. It is important to note that the strongest predictor of AF recurrence in that trial was the presence of longstanding pAF (hazard ratio 9.3, confidence interval 2.2-38.5). Another study by Edgerton et $\mathrm{al}^{32}$ showed worse results in patients with longstanding persistent AF, demonstrating $56 \%$ freedom from AF, with only $35 \%$ of patients also off of AADs by Holter/event monitor at 6 months. The 1-year results were not reported. Even with incomplete follow-up, these data stress the necessity of appropriate patient selection.

More recently, the Atrial Fibrillation Catheter Ablation Versus Surgical Ablation Treatment (FAST) Trial, which was a 2-center, randomized prospective clinical trial, compared catheter-based ablation with thoracoscopic PVI in patients with AAD-refractory AF and either LA dilatation and hypertension or failed prior catheter ablation (Tables 1,2). ${ }^{27}$ The lesion sets utilized in that study differed by center and at the discretion of the surgeons, with additional lesions described in Table 1 . The study demonstrated that the 12-month freedom from ATAs and AADs was $37 \%$ for the catheter ablation group and $66 \%$ for the PVI group $(\mathrm{P}=0.0022)$. Therefore, although results with surgical PVI were not as good as a full biatrial Cox-Maze lesion set, they were superior to catheter-based ablation in pa- 


\begin{tabular}{|c|c|c|c|c|c|c|c|c|c|c|c|c|c|}
\hline \multirow[b]{2}{*}{ Author } & \multirow{2}{*}{$\begin{array}{c}\text { No. } \\
\text { patients } \\
\text { in hybrid } \\
\text { group }\end{array}$} & \multirow[b]{2}{*}{$\begin{array}{c}\text { Surgical } \\
\text { chest } \\
\text { access }\end{array}$} & \multirow[b]{2}{*}{$\begin{array}{l}\text { Single- } \\
\text { stage }\end{array}$} & \multirow[b]{2}{*}{$\begin{array}{l}\text { Surgical } \\
\text { ablation } \\
\text { technology }\end{array}$} & \multicolumn{9}{|c|}{ Lesion set performed ${ }^{\star}$} \\
\hline & & & & & $\begin{array}{l}\text { LAA } \\
\text { exclusion/ } \\
\text { excision }\end{array}$ & PVI & Box & GP & LOM & $\begin{array}{c}\text { SVC/IVC/ } \\
\text { BCL }\end{array}$ & MIL & CTI & ALAL \\
\hline Muneretto ${ }^{54}$ & 36 & $\begin{array}{l}\text { R-sided } \\
\text { VATS }\end{array}$ & $\mathrm{N}$ & $\begin{array}{l}\text { Monopolar } \\
\text { RF probe }\end{array}$ & $\mathrm{N}$ & Y & $Y$ & $\mathrm{Y}^{\dagger}$ & $\mathrm{N}$ & $\mathrm{N} / \mathrm{N} / \mathrm{N}$ & $\mathrm{N}$ & $\begin{array}{c}\mathrm{Y} \\
(21)\end{array}$ & $Y^{\ddagger}$ \\
\hline Krul| ${ }^{49}$ & 31 & $\begin{array}{c}\text { Bilateral } \\
\text { VATS }\end{array}$ & Y & $\begin{array}{l}\text { Bipolar RF } \\
\text { clamp/pen }\end{array}$ & Y & Y & $\begin{array}{c}Y^{* *} \\
( \pm 13)\end{array}$ & $\begin{array}{c}Y \\
(30)\end{array}$ & $Y$ & $\mathrm{~N} / \mathrm{N} / \mathrm{N}$ & $\begin{array}{c}Y \\
(13)\end{array}$ & $\mathrm{N}$ & $\mathrm{N}$ \\
\hline Mahapatra $^{52}$ & 15 & $\begin{array}{l}\text { Bilateral } \\
\text { VATS }\end{array}$ & $\mathrm{N}$ & $\begin{array}{l}\text { Bipolar RF } \\
\text { clamp/pen }\end{array}$ & $\begin{array}{c}Y \\
(14)\end{array}$ & Y & $\mathrm{N}$ & $\mathrm{Y}$ & $Y$ & $\mathrm{Y} / \mathrm{N} / \mathrm{N}$ & $\mathrm{Y}$ & Y & $Y$ \\
\hline La Meir ${ }^{50}$ & 19 & $\begin{array}{l}\text { R-sided } \\
\text { VATS }\end{array}$ & Y & $\begin{array}{l}\text { Monopolar } \\
\text { RF probe }\end{array}$ & $\mathrm{N}$ & Y & $Y$ & Y & $\mathrm{N}$ & $\mathrm{N} / \mathrm{N} / \mathrm{N}$ & $\begin{array}{c}Y \\
(3)\end{array}$ & $\begin{array}{l}Y \\
(2)\end{array}$ & $\mathrm{N}$ \\
\hline La Meir ${ }^{51}$ & 35 & $\begin{array}{l}\text { Bilateral } \\
\text { VATS }\end{array}$ & $Y$ & $\begin{array}{l}\text { Bipolar RF } \\
\text { clamp/pen }\end{array}$ & $\begin{array}{c}\mathrm{Y} \\
(15)\end{array}$ & Y & $\begin{array}{c}Y \\
(31)\end{array}$ & Y & $\mathrm{N}$ & $\begin{array}{c}Y(8) / Y(3) / \\
Y(10)\end{array}$ & $\begin{array}{l}Y \\
(7)\end{array}$ & $\begin{array}{l}Y \\
(3)\end{array}$ & $\mathrm{N}$ \\
\hline Pison $^{53}$ & 26 & $\begin{array}{l}\text { Bilateral } \\
\text { VATS }\end{array}$ & Y & $\begin{array}{l}\text { Bipolar RF } \\
\text { clamp/pen }\end{array}$ & $\begin{array}{l}Y \\
(7)\end{array}$ & Y & $\begin{array}{c}Y \\
(22)\end{array}$ & $\mathrm{N}$ & $\mathrm{N}$ & $\begin{array}{c}Y(7) / Y(3) / \\
Y(9)\end{array}$ & $\begin{array}{l}Y \\
(3)\end{array}$ & $\begin{array}{l}Y \\
(3)\end{array}$ & $\mathrm{N}$ \\
\hline
\end{tabular}

${ }^{*}(\mathrm{n})$ is specified when not all patients received a particular ablation line. ${ }^{* *} 13$ patients had an additional superior PV connecting line and an unspecified subset of those also had an inferior PV connecting line. ${ }^{\dagger} \mathrm{GP}$ were presumably taken with epicardial fat removal prior to ablation with the unipolar probe. Removal was not confirmed. $\neq$ When firing foci were identified within the PVs, an additional PV antral line was performed even in the presence of an effective box lesion $(n=14)$. Additional lines were also made to target complex atrial fractionated electrograms ( $n=6)$. BCL, bilateral caval connecting line; CTI, cavotricuspid isthmus; IVC, inferior vena cava circumferential lesion; MIL, mitral isthmus lesion; RF, radiofrequency; SVC, superior vena cava circumferential lesion; R, right. Other abbreviations as in Table 1.

tients with unfavorable atrial substrates and more complex disease. It is important to note that results from this study were, again, superior for patients with PAF as opposed to those with pAF (69\% vs. $56 \%$, Table 2 ).

The success of PVI is further decreased in patients undergoing concomitant operations, which is critical, because in the current era the majority of ablative procedures for AF are performed in patients already undergoing other open heart surgery, particularly mitral valve operations. In the setting of mitral valve replacement \pm other concomitant operations (including aortic and tricuspid valve procedures and atrial septal defect closure), one study that used cryoablation showed $61 \%$ freedom from "chronic AF" and only $17 \%$ freedom from chronic AF and AADs at a follow-up of $31 \pm 16$ months. ${ }^{23}$ Those results cannot be directly compared with 1-year data, but they are telling regarding the long-term durability of simple PVI in this population.

The data highlight the need to fully understand the electrophysiological substrate of AF in order to perform the optimal operation for any given individual patient. At present, surgical PVI is recommended for selected patients with lone PAF. It should be avoided in patients with LA diameter $\geq 4.5 \mathrm{~cm}$ because they are more likely to have non-PV triggers. It can be performed in patients with pAF, but results have been variable, and a more extensive lesion set is likely needed to achieve more consistent results.

\section{Extended LA Lesion Sets}

\section{Surgical Technique}

The techniques for performing extended LA lesion sets differ significantly between surgeons and centers, and various ablation technologies have been used from both the endocardial and epicardial surface. All of these procedures have incorporated some subset of the LA lesion set of the CMP. Typically, PVI is performed and may be accompanied by a lesion to the mitral annulus with or without removal of the LAA. An additional line from the LAA to the left superior PV has also been sometimes included.

\section{Surgical Results}

The effectiveness of extended LA lesion sets has been variable. The best results have been demonstrated with the contemporary series of hybrid patients with outcomes reported in accordance with recent guidelines (discussed in the next section, Tables 3,4). ${ }^{3}$ However, not all studies have achieved the same degree of success with similar lesion sets. Although the increased success rates in these series could be partly accounted for by the small number of patients, higher failure rates in other reports suggest that in some cases the problem is with patient selection. Regardless, even studies published before the acceptance of recent guidelines prove the value of LA lesion sets in the surgical management of AF. In a randomized trial of patients with pAF undergoing mitral valve surgery and RF ablation (RFA) of the LA vs. mitral valve surgery alone, NSR was present in $44.4 \%$ of RFA patients at 1-year follow-up, compared with $4.5 \%$ in the mitral valve surgery only group. ${ }^{33}$ In that trial, ablation was performed using only a monopolar RF device applied from the endocardial surface, which likely had limited efficacy in creating transmural lesions and would have made adequate ablation of the mitral isthmus impossible. ${ }^{18}$ Although the results were suboptimal, ${ }^{11,12}$ it is important to note that ablation with only a LA lesion set was superior to no intervention for patients with AF, both in this study as well as in numerous other randomized trials of patients undergoing concomitant cardiac surgery. ${ }^{33-39}$

Data have previously demonstrated the importance of many of the lines that comprise the LA lesion set of the CMP. The significance of the LA isthmus lesion in patients with permanent $\mathrm{AF}$ was shown by a retrospective analysis from Gillinov et al. ${ }^{17}$ Patients are at risk for late LA flutter if the isthmus line is either incomplete or omitted. In a randomized trial, Gaita et $\mathrm{al}^{40}$ enrolled 105 patients with permanent $\mathrm{AF}$ and valvular disease and examined PVI alone vs. two alternate lesion sets that both included ablation of the LA isthmus. They reported that freedom from AF off AADs at 2-year follow-up was only seen in $20 \%$ in the PVI group vs. $57 \%$ in the other groups $(\mathrm{P}<0.006)$. Moreover, we have demonstrated the importance of a "box" lesion around the PVs and entire posterior LA. ${ }^{12}$ Therefore, most of the LA Cox-Maze lesion set is likely need- 


\begin{tabular}{|c|c|c|c|c|c|c|c|}
\hline \multirow{2}{*}{ Author } & \multirow{2}{*}{$\begin{array}{l}\text { No. patients in } \\
\text { hybrid group }\end{array}$} & \multirow{2}{*}{$\begin{array}{l}\text { Average LA } \\
\text { size }(\mathrm{cm})\end{array}$} & \multirow{2}{*}{$\begin{array}{l}\text { Follow-up } \\
\text { endpoint }\end{array}$} & \multirow{2}{*}{ Monitoring type } & \multicolumn{3}{|c|}{ Freedom from ATAs and AADs } \\
\hline & & & & & Overall & PAF & pAF/LSP AF" \\
\hline Muneretto $^{54 *}$ & 36 & $5.1 \pm 1.0$ & $\begin{array}{c}\text { Mean }=30 \\
\text { months (range } \\
1-58 \text { months) }\end{array}$ & $\begin{array}{l}\text { Implantable, continuous } \\
\text { loop recorder } \\
\text { (REVEAL XT) }\end{array}$ & $78 \% \%^{\ddagger}$ & - & $78 \%$ ** \\
\hline Krul ${ }^{49}$ & 31 & $4.7 \pm 0.7$ & 12 months & 24-h Holter & $86 \%$ & $92 \%$ & $80 \%$ \\
\hline Mahapatra $^{52}$ & 15 & $5.2 \pm 1.0$ & $21 \pm 5$ months & $\begin{array}{c}\text { EKG/7-day and } \\
\text { 24-h Holter }{ }^{\dagger}\end{array}$ & - & - & $87 \%$ \\
\hline La Meir 50 & 19 & $5.0 \pm 0.5$ & 12 months & 7-day Holter & $37 \%$ & $60 \%$ & $50 \% / 20 \%$ \\
\hline La Meir ${ }^{51}$ & 35 & $5.2 \pm 0.5$ & 12 months & 7-day Holter & $86 \%$ & $88 \%$ & $88 \% / 82 \%$ \\
\hline Pison $^{53}$ & 26 & NS & 12 months & 7-day or 24-h Holter & $92 \%$ & $93 \%$ & $90 \%$ \\
\hline
\end{tabular}

*This group has published 3 progressively updated series. The second largest was selected for inclusion in the table because the most recent does not present freedom from AF off AADs. ${ }^{\star *}$ Freedom from AF was considered to be absence of AF episodes lasting $>5$ min and an overall burden of $0.5 \%$ of time spent in AF on a monthly basis. Freedom from ATAs was not considered for reporting. ${ }^{\dagger} E K G$ s were performed at 1,3 , 6,9 and 12 months and then every 6 months thereafter. 7-day, continuous, auto-triggered monitors were recorded at 3 , 6 and 12 months, and 24-hr Holter monitors were performed at 9, 18 and 24 months. Freedom from ATAs and AADs was not reported at any fixed time point. $¥$ Where only 1 number is reported, persistent AF and LSP AF patients were analyzed as 1 group. Other abbreviations as in Table 2.

ed to ensure a high success rate.

The importance of the RA lesions included in the CMP is difficult to ascertain, as biatrial vs. LA surgical ablation has never been compared in a randomized clinical trial. Although some evidence suggests a LA lesion set is as effective as a biatrial lesion set in patients with chronic AF undergoing concomitant open heart procedures, ${ }^{41}$ other studies have not substantiated this finding. A meta-analysis of the published literature compared 2,260 patients from 24 studies of biatrial lesion sets to 965 patients from 13 studies of LA lesion sets. ${ }^{42}$ The analysis revealed that biatrial lesion sets resulted in a significantly higher 1-year freedom from $\mathrm{AF}$ when compared with LA lesion sets alone ( $89 \%$ vs. $76 \%, \mathrm{P}=0.001)$, and this did not change at either 2 or 3 years following ablation. These results are consistent with our intraoperative mapping experience, which showed distinct regions of stable dominant frequencies in the LA, indicating stable LA origins for AF, only $30 \%$ of the time. ${ }^{43}$ In $12 \%$ of patients the AF originated from the RA, and in almost half of the patients mapped, the origin was unstable and moved around the atria. It must be kept in mind that recurrent RA flutter or tachycardia is a well-known complication of omitting a RA cavotricuspid isthmus line. ${ }^{44}$

The most recent study to examine the importance of RA lesion sets suggested that although extended LA lesion sets were superior to PVI in terms of 1-year freedom from $\mathrm{AF}$ ( $76 \%$ vs. $53 \%, \mathrm{P}<0.001)$, the addition of a RA lesion set did not confer additional efficacy ( $76 \%$ vs. $80 \%, \mathrm{P}=\mathrm{NS}){ }^{45}$ Unfortunately, because of uncorrected differences in baseline patient characteristics between groups, the heterogeneity of lesion sets and ablation technology, the performance of multiple subanalyses, rhythm follow-up with only electrocardiography and failure to report freedom from AADs, these data are extremely difficult to interpret. Moreover, the significant differences between groups suggest that there was a fairly prominent uncontrolled selection bias in what lesion sets were chosen for different patients.

These authors found similar differences between lesion sets ${ }^{45}$ when operations were performed in patients undergoing concomitant mitral valve surgery. An ongoing NIH sponsored clinical trial comparing biatrial ablation, extended LA ablation and no treatment in AF patients undergoing mitral valve surgery should help clarify this issue (ClinicalTrials.gov identifier: NCT00903370). With the advent of ablation technology, which has simplified the performance of the operation, it is our belief that all patients undergoing AF ablation with concomi- tant cardiac surgery should have at least the full Cox-Maze LA lesion set, and in most patients a biatrial lesion set should be performed if it can be done without adding to the morbidity of the procedure.

\section{Hybrid Approach}

\section{Surgical Technique}

The hybrid approach is a relatively new method that combines minimally invasive, epicardial AF surgery, electrophysiology (EP) mapping and catheter-based endocardial ablation in an attempt to overcome the shortcomings of each technique. ${ }^{46-50}$ The surgeon may isolate the posterior LA, ablate the ganglionated plexus and ligament of Marshall (LOM), isolate the vena cavae and begin a mitral isthmus line thoracoscopically. The addition of the endocardial step allows electrophysiologists to "touch-up" any gaps in epicardial lesions and create or complete lesions in areas that cannot be reached epicardially, such as the cavotricuspid and LA isthmus. Theoretical advantages to the hybrid approach are (1) the ability to confirm conduction block across lesions, (2) the ability to close identified gaps that might result in postoperative arrhythmias or long-term failures, (3) minimization of surgical injury to structures not easily reached, (4) elimination of risk to the phrenic nerve and esophagus from catheter ablation because the surgeon can protect these structures, (5) reduced risk of tamponade compared with catheter-based ablation alone because the pericardium is open and (6) reduced risk of embolism from coagulation caused by endocardial ablations because fewer endocardial ablations are needed.

Although a sequential, 2-stage procedure has been described, ${ }^{49,51}$ many centers have elected to perform hybrid ablation as a single-step procedure (Table 3 ). Since not all sequential patients have inducible atrial flutter/fibrillation or gaps in ablation lines, the argument has been made that it is more cost-effective to wait to perform endocardial ablation until patients develop signs of recurrent arrhythmias. ${ }^{49}$ However, other groups believe that a 1-stage procedure carries the highest chance of initial success and further benefits patients by avoiding a subsequent procedure and rehospitalization.

Thoracoscopic access to the chest is typically gained with bilateral port placement. A right-sided approach was tested by La Meir et al using a monopolar RF probe, ${ }^{47}$ but this was abandoned because of the inability to create transmural ablation lines and poor resultant outcomes (Table 4). Others have 
persisted with the right-sided approach using similar devices, but have reported superior results. ${ }^{51-53}$ However, direct comparisons between studies are difficult, as both the follow-up methodology and definitions vary.

The hybrid operation is performed under general anesthesia, without $\mathrm{CPB}$, using a double lumen endotracheal tube for selective lung ventilation. Typically, the chest is entered first from the right and then from the left using one 5-mm and two 12-mm ports placed as described previously for thoracoscopic PVI. Lesion sets and ablation algorithms, thus subsequent steps, vary between groups (Table 3 ). After opening the pericardium, high-frequency stimulation (HFS) of the right vagal nerve and the 4 major ganglionated plexi (GP) sites may be performed, and active autonomic GP, identified by prolongation of the ventricular cycle length by $\geq 50 \%$ during HFS, may be ablated using a unidirectional, bipolar RF pen. The endpoint for GP ablation, when performed, is elimination of a vagal response to stimulation. At our center, we do not perform GP stimulation and feel that the data are not sufficient to warrant its use. PVI using a bipolar RF clamp is then completed as described previously. The roof line (connecting both superior PVs) and the inferior line (connecting both inferior PVs) may be created using a bipolar RF pen positioned through the transverse and oblique sinuses. Despite data confirming the importance of complete posterior LA isolation, these additional lesions are not universally performed.

Most authors have elected to create a mitral isthmus line starting from the antrum of the left inferior PV and extending across the coronary sinus for patients in whom AF persists. ${ }^{46-48,50}$ This is completed with a combination of epicardial and endocardial ablation. Of note, once this lesion has been started epicardially, failure to complete it from the endocardial side is proarrhythmic and can leave the patient susceptible to the development of atrial flutter. Moreover, some elect to perform circumferential SVC and/or IVC lesions with or without an IVC to SVC connecting line, particularly for patients with pAF or LSP AF and large atrial volumes. For circumferential SVC lesions, care should be taken to clamp above the SVCRA junction in order to avoid the SA node.

The endocardial portion of the procedure begins with a femoral venous approach to introduce His bundle and coronary sinus catheters under fluoroscopic and TEE guidance, and a single transseptal puncture is made using a long $8 \mathrm{~F}$ sheath in order to access the left heart. Systemic heparinization is performed to keep the activated clotting time $>300 \mathrm{~s}$. Both epicardial and endocardial pacing are used to demonstrate entrance and exit block from the PVs. Although not universally performed, in the case of NSR following PVI, some centers attempt to induce AF by pacing the coronary sinus multiple times at the shortest cycle length capable of achieving 1:1 atrial capture. If $\mathrm{AF}$ is not inducible, isoproterenol is infused at $10-30 \mu \mathrm{g} / \mathrm{min}$. Additional linear lesions are carried out for inducible AF or AF that never terminated, and conduction gaps are repaired endocardially through the sheath in the LA. Gaps are defined as low amplitude and fragmented or narrowly split double atrial potentials, and the precise location of the epicardial lesion is identified under fluoroscopy with the bipolar pen in situ. Furthermore, endocardial creation of a cavotricuspid isthmus (CTI) line is performed for patients with a history of RA flutter or for patients in whom that arrhythmia manifests during the operation.

LAA exclusion/excision can be performed with a stapler or clip. Currently published series have based the decision to manage the LAA on factors such as the $\mathrm{CHADS}_{2}$ score, and, as a result, close to $50 \%$ of patients retained their LAA post- operatively. We advocate LAA exclusion or excision in all patients as a means to reduce postoperative stroke and facilitate discontinuation of warfarin.

\section{Surgical Results}

The hybrid approach has yielded good early results, even with a focus on difficult populations, such as patients with pAF or LSP AF who have failed previous catheter-based ablation (Table 4). ${ }^{49}$ A shortcoming to these procedures has been that the overall operative time is longer than for traditional surgical ablation alone, ${ }^{11}$ minimally invasive ablation (median $268 \mathrm{~min}$, interquartile range [IQR] 186-477 vs. median $127 \mathrm{~min}, \mathrm{IQR}$ $97-188, \mathrm{P}=0.001)^{48}$ or percutaneous catheter ablation $(450 \pm 20$ vs. $302 \pm 65 \mathrm{~min}, \mathrm{P}=0.01)^{49}$ alone, although procedure times have varied by center and with the extent of the lesion set performed. Early studies have demonstrated improvements over both non-hybrid minimally invasive surgery and catheterbased ablation, and in appropriately selected patients, results are comparable to those obtained with a Cox-Maze lesion set. ${ }^{11}$

La Meir et al compared hybrid surgery $(n=35)$ to non-hybrid thoracoscopic ablation $(n=28)$ and found a trend towards higher freedom from postoperative ATAs and AADs in the hybrid group (91\% [32/35] vs. 82\% [23/28], $\mathrm{P}=0.07) .{ }^{48}$ When comparing only patients with LSP AF, this difference was more drastic $(82 \%$ [9/11] vs. $44 \%$ [4/9], $\mathrm{P}=0.001)$, and the time-related prevalence of $\mathrm{AF}$ was significantly lower (8\% [5.1-11.6] vs. $15 \%$ [11.6-18.3], $\mathrm{P}=0.04)$. In a study by Han et $\mathrm{al}^{29}$ that looked at thoracoscopic PVI, GP and LOM ablation, and LAA exclusion, 1-year freedom from ATAs and AADs was $65 \%$ (28/43). They went on to perform catheter ablation after recurrence of $\mathrm{AF}$ and by doing so increased that rate to $74 \%$ (32/43).

With respect to catheter-based approaches alone, previous studies have demonstrated poor efficacy for patients with prior failed catheter ablation or risk factors for failure, such as enlarged LA. ${ }^{27}$ Mahapatra et $\mathrm{a}^{49}$ directly compared the hybrid approach in 15 patients with pAF or LSP AF who had failed catheter ablation with 30 matched patients who underwent repeat catheter ablation. Freedom from ATAs and AADs was improved with the hybrid procedure (87\% [13/15] vs. 53\% [16/30], $\mathrm{P}=0.04$, at a mean follow-up of $20.7 \pm 4.5$ months). As a result of these early reports, a multicenter trial, the Dual Epicardial Endocardial Persistent Atrial Fibrillation (DEEPAF) trial, scheduled to finish at the end of 2013, is underway to evaluate the safety and efficacy of the hybrid approach using a bipolar RF system.

Early studies have supported the safety of the hybrid approach, although this varies widely by center, and in one study the incidence of conversion to sternotomy for uncontrollable bleeding was $10 \%(3 / 31) .{ }^{46}$ Other complications, such as hemothorax, pneumothorax, pacemaker requirement and pneumonia, have been reported. ${ }^{46,50}$ Our own experience suggests a higher complication rate with the hybrid approach, and bleeding can be difficult to manage. At present, most of the series are small with limited follow-up, and this remains a procedure that should only be performed at specialized centers that are committed to close long-term follow-up of their patients. The advantage of a hybrid approach over catheter ablation or surgical ablation remains unclear. Finally, it is possible that decisions to leave the LAA intact, as done by several groups performing hybrid procedures, could lead to an increased incidence of long-term, postoperative stroke when compared with that seen following the CMP IV. 


\section{Ganglionated Plexus Ablation}

Both the extrinsic and intrinsic cardiac anatomic nervous systems (ECANS and ICANS, respectively) regulate cardiac function and electrophysiology. ${ }^{54,55}$ Parasympathetic and sympathetic fibers that comprise part of the ECANS enter the heart along the PVs, SVC and aorta and form synaptic junctions with fibers of the ICANS within the GP. It is thought that parasympathetic tone can result in a shortening of refractory periods and, combined with sympathetic tone, can facilitate triggered activity. As such, studies have demonstrated that local autonomic ganglia in the GP can play a role in the initiation and maintenance of AF. ${ }^{56}$ The GP are concentrated in 4 main fat pads: (1) lateral to the right PV, (2) below the IVC on the LA, (3) at the junction of the SVC and the aorta, and (4) anterior to the superior left PV. Both PV myocardial sleeves and adjacent atrial muscle are innervated by these plexi. As a result, some surgeons have incorporated GP ablation into their lesion sets in the hope of increasing procedural efficacy (Tables 1-4), but the benefit of GP ablation is unclear. Although several series in the hybrid procedure literature have achieved excellent results with GP ablation as part of their lesion set (Tables 3-4), the best results have been reported by Pison et al without GP ablation..$^{50}$ No reports have compared approaches, either retrospectively or as part of randomized clinical trials. It can at least be confidently stated that GP ablation alone does not effectively treat AF. Katritsis et al used catheter-based GP ablation alone to treat 19 patients with PAF and noted that $14(74 \%)$ had recurrent AF during 1-year follow-up. ${ }^{57}$

Moreover, the effects of vagal denervation and the longterm efficacy of GP ablation have not been clearly defined. Experimental evidence from our laboratory and others has demonstrated recovery of autonomic function in as few as 4 weeks after GP ablation. ${ }^{55}$ It is worrisome that reinnervation may not be homogeneous and could result in a more arrhythmogenic substrate. One canine study showed that partial RA vagal denervation actually facilitated vagally mediated $\mathrm{AF}$ by causing conduction block at the site of ablation and macroreentrant activation around the block. ${ }^{58}$ Another recent canine study demonstrated that selective ablation of the GP located at the junction of the SVC and aorta prolonged the effective refractory period (ERP) acutely but shortened regional ERPs and increased the AF/AT burden chronically. ${ }^{59}$ This suggests that ECANS activity might tonically inhibit rather than stimulate ICANS activity, which is consistent with the fact that the strength of vagal stimulation that is used to induce AF is often not physiological.

Because of a lack of evidence demonstrating the efficacy of adding GP ablation to standard lesion sets and because of uncertainty regarding the effects of vagal denervation, we do not perform GP ablation to treat AF in our practice. GP ablation should be reserved for centers participating in clinical trials.

\section{Conclusions}

Although various strategies exist for the management of AF, the CMP remains the current gold standard. It is effective in patients with all types of $\mathrm{AF}$, including patients with difficult electroanatomic substrates and with concomitant cardiac surgery. ${ }^{11,12}$ In patients with AF undergoing mitral valve procedures, a concomitant Cox-Maze IV lesion set incurs minimal additional cross-clamp time and overall operative risk, and it has been demonstrated to result in superior freedom from $\mathrm{AF}$ when compared with mitral valve surgery alone. ${ }^{60}$ The CoxMaze lesion set has also been shown to have a high success rate in patients undergoing CABG ${ }^{61}$ It is recommended that a biatrial CMP be performed in patients with AF that are undergoing on-pump cardiac surgery for another indication. In patients with PAF undergoing off-pump CABG, we perform PVI alone because of the reasonably good results reported with this strategy. Nonetheless, in patients with LSP AF, the results for PVI alone have been suboptimal, indicating a need for a more extensive approach. The extent to which the hybrid approach will be adopted for the treatment of lone AF and what role it will play in relation to the standard Cox-Maze IV has yet to be determined.

In conclusion, the development of ablation technology has dramatically changed the field of AF surgery by transforming a technically demanding procedure into one that is accessible to the majority of surgeons. It has also introduced the possibility of minimally invasive approaches. As we learn more about the mechanisms of AF and develop improved diagnostic technologies capable of precisely locating the arrhythmogenic substrate, it will become possible to tailor specific lesion sets and ablation modalities to individual patients. This would make the surgical treatment of AF more effective and applicable to a larger population of patients.

\section{Disclosures}

R.J.D. is a consultant for Medtronic and AtriCure, and has received research and educational funding from Estech, AtriCure and Edwards. None of the other authors have any disclosures.

\section{References}

1. Zimetbaum P. Antiarrhythmic drug therapy for atrial fibrillation. Circulation 2012; 125: 381-389.

2. Corley SD, Epstein AE, DiMarco JP, Domanski MJ, Geller N, Greene HL, et al. Relationships between sinus rhythm, treatment, and survival in the Atrial Fibrillation Follow-up Investigation of Rhythm Management (AFFIRM) study. Circulation 2004; 109: 1509-1513.

3. Calkins H, Kuck KH, Cappato R, Brugada J, Camm AJ, Chen SA, et al. 2012 HRS/EHRA/ECAS Expert Consensus Statement on catheter and surgical ablation of atrial fibrillation: Recommendations for patient selection, procedural techniques, patient management and follow-up, definitions, endpoints, and research trial design: A report of the Heart Rhythm Society (HRS) Task Force on Catheter and Surgical Ablation of Atrial Fibrillation. Developed in partnership with the European Heart Rhythm Association (EHRA), a registered branch of the European Society Of Cardiology (ESC) and the European Cardiac Arrhythmia Society (ECAS); and in collaboration with the American College of Cardiology (ACC), American Heart Association (AHA), the Asia Pacific Heart Rhythm Society (APHRS), and the Society of Thoracic Surgeons (STS). Endorsed by the governing bodies of the American College Of Cardiology Foundation, the American Heart Association, the European Cardiac Arrhythmia Society, the European Heart Rhythm Association, the Society of Thoracic Surgeons, the Asia Pacific Heart Rhythm Society, and the Heart Rhythm Society. Heart Rhythm 2012; 9: 632-696 e621.

4. Pet M, Robertson JO, Bailey M, Guthrie TJ, Moon MR, Lawton JS, et al. The impact of CHADS(2) score on late stroke after the Cox Maze procedure. J Thorac Cardiovasc Surg 2012 July 17, doi:10. 1016/j.jtcvs.2012.03.087.

5. Williams JM, Ungerleider RM, Lofland GK, Cox JL. Left atrial isolation: New technique for the treatment of supraventricular arrhythmias. J Thorac Cardiovasc Surg 1980; 80: 373-380.

6. Leitch JW, Klein G, Yee R, Guiraudon G. Sinus node-atrioventricular node isolation: Long-term results with the 'corridor' operation for atrial fibrillation. J Am Coll Cardiol 1991; 17: 970-975.

7. Feinberg MS, Waggoner AD, Kater KM, Cox JL, Lindsay BD, Perez JE. Restoration of atrial function after the maze procedure for patients with atrial fibrillation: Assessment by doppler echocardiography. Circulation 1994; 90: II285-II292.

8. Cox JL, Ad N, Palazzo T. Impact of the maze procedure on the stroke rate in patients with atrial fibrillation. J Thorac Cardiovasc Surg 1999; 118: 833-840. 
9. Cox JL, Schuessler RB, Lappas DG, Boineau JP. An 8 1/2-year clinical experience with surgery for atrial fibrillation. Ann Surg 1996; 224: 267-273; discussion 273-275.

10. Prasad SM, Maniar HS, Camillo CJ, Schuessler RB, Boineau JP, Sundt TM 3rd, et al. The Cox Maze III procedure for atrial fibrillation: Long-term efficacy in patients undergoing lone versus concomitant procedures. J Thorac Cardiovasc Surg 2003; 126: 1822-1828.

11. Weimar T, Bailey MS, Watanabe Y, Marin D, Maniar HS, Schuessler $\mathrm{RB}$, et al. The Cox-Maze IV procedure for lone atrial fibrillation: A single center experience in 100 consecutive patients. J Interv Card Electrophysiol 2011; 31: 47-54.

12. Damiano RJ Jr, Schwartz FH, Bailey MS, Maniar HS, Munfakh NA, Moon MR, et al. The Cox Maze IV procedure: Predictors of late recurrence. J Thorac Cardiovasc Surg 2011; 141: 113-121.

13. Lall SC, Melby SJ, Voeller RK, Zierer A, Bailey MS, Guthrie TJ, et al. The effect of ablation technology on surgical outcomes after the Cox-Maze procedure: A propensity analysis. J Thorac Cardiovasc Surg 2007; 133: 389-396.

14. Voeller RK, Zierer A, Lall SC, Sakamoto S, Chang NL, Schuessler $\mathrm{RB}$, et al. The effects of the Cox Maze procedure on atrial function. $J$ Thorac Cardiovasc Surg 2008; 136: 1257-1264, 1264 e1251 - e1253.

15. Gaynor SL, Diodato MD, Prasad SM, Ishii Y, Schuessler RB, Bailey MS, et al. A prospective, single-center clinical trial of a modified cox maze procedure with bipolar radiofrequency ablation. J Thorac Cardiovasc Surg 2004; 128: 535-542.

16. Weimar T, Schena S, Bailey MS, Maniar HS, Schuessler RB, Cox JL, et al. The Cox-Maze procedure for lone atrial fibrillation: A singlecenter experience over 2 decades. Circ Arrhythm Electrophysiol 2012; 5: $8-14$.

17. Gillinov AM, McCarthy PM, Blackstone EH, Rajeswaran J, Pettersson G, Sabik JF, et al. Surgical ablation of atrial fibrillation with bipolar radiofrequency as the primary modality. J Thorac Cardiovasc Surg 2005; 129: $1322-1329$.

18. Schuessler RB, Lee AM, Melby SJ, Voeller RK, Gaynor SL, Sakamoto $\mathrm{S}$, et al. Animal studies of epicardial atrial ablation. Heart Rhythm 2009; 6: S41-S45.

19. Dawson AG, Asopa S, Dunning J. Should patients undergoing cardiac surgery with atrial fibrillation have left atrial appendage exclusion? Interact Cardiovasc Thorac Surg 2010; 10: 306-311.

20. Albage A, Peterffy M, Kallner G. Learning what works in surgical cryoablation of atrial fibrillation: Results of different application techniques and benefits of prospective follow-up. Interact Cardiovasc Thorac Surg 2011; 13: 480-484.

21. Beyer E, Lee R, Lam BK. Point: Minimally invasive bipolar radiofrequency ablation of lone atrial fibrillation: Early multicenter results. J Thorac Cardiovasc Surg 2009; 137: 521-526.

22. La Meir M, Gelsomino S, Luca F, Pison L, Colella A, Lorusso R, et al. Minimal invasive surgery for atrial fibrillation: An updated review. Europace 2013; 15: 170-182.

23. Tada H, Ito S, Naito S, Hasegawa Y, Kurosaki K, Ezure M, et al. Long-term results of cryoablation with a new cryoprobe to eliminate chronic atrial fibrillation associated with mitral valve disease. Pacing Clin Electrophysiol 2005; 28(Suppl 1): S73-S77.

24. Wolf RK, Schneeberger EW, Osterday R, Miller D, Merrill W, Flege $\mathrm{JB} \mathrm{Jr}$, et al. Video-assisted bilateral pulmonary vein isolation and left atrial appendage exclusion for atrial fibrillation. J Thorac Cardiovasc Surg 2005; 130: 797-802.

25. Wudel JH, Chaudhuri P, Hiller JJ. Video-assisted epicardial ablation and left atrial appendage exclusion for atrial fibrillation: Extended follow-up. Ann Thorac Surg 2008; 85: 34-38.

26. Bagge L, Blomstrom P, Nilsson L, Einarsson GM, Jideus L, Blomstrom-Lundqvist C. Epicardial off-pump pulmonary vein isolation and vagal denervation improve long-term outcome and quality of life in patients with atrial fibrillation. J Thorac Cardiovasc Surg 2009; 137: 1265-1271

27. Boersma LV, Castella M, van Boven W, Berruezo A, Yilmaz A, Nadal M, et al. Atrial fibrillation catheter ablation versus surgical ablation treatment (FAST): A 2-center randomized clinical trial. Circulation 2012; 125: 23-30.

28. Edgerton JR, Brinkman WT, Weaver T, Prince SL, Culica D, Herbert $\mathrm{MA}$, et al. Pulmonary vein isolation and autonomic denervation for the management of paroxysmal atrial fibrillation by a minimally invasive surgical approach. J Thorac Cardiovasc Surg 2010; 140: 823-828.

29. Han FT, Kasirajan V, Kowalski M, Kiser R, Wolfe L, Kalahasty G, et al. Results of a minimally invasive surgical pulmonary vein isolation and ganglionic plexi ablation for atrial fibrillation: Single-center experience with 12-month follow-up. Circ Arrhythm Electrophysiol 2009; 2: 370-377.

30. McClelland JH, Duke D, Reddy R. Preliminary results of a limited thoracotomy: New approach to treat atrial fibrillation. J Cardiovasc
Electrophysiol 2007; 18: 1289-1295.

31. Wang JG, Li Y, Shi JH, Han J, Cui YQ, Luo TG, et al. Treatment of long-lasting persistent atrial fibrillation using minimally invasive surgery combined with irbesartan. Ann Thorac Surg 2011; 91: $1183-$ 1189.

32. Edgerton JR, Edgerton ZJ, Weaver T, Reed K, Prince S, Herbert MA, et al. Minimally invasive pulmonary vein isolation and partial autonomic denervation for surgical treatment of atrial fibrillation. Ann Thorac Surg 2008; 86: 35-38; discussion 39.

33. Doukas G, Samani NJ, Alexiou C, Oc M, Chin DT, Stafford PG, et al. Left atrial radiofrequency ablation during mitral valve surgery for continuous atrial fibrillation: A randomized controlled trial. JAMA 2005; 294: 2323-2329.

34. Abreu Filho CA, Lisboa LA, Dallan LA, Spina GS, Grinberg M, Scanavacca M, et al. Effectiveness of the maze procedure using cooled-tip radiofrequency ablation in patients with permanent atrial fibrillation and rheumatic mitral valve disease. Circulation 2005; 112: I20-I25.

35. Blomstrom-Lundqvist C, Johansson B, Berglin E, Nilsson L, Jensen SM, Thelin S, et al. A randomized double-blind study of epicardial left atrial cryoablation for permanent atrial fibrillation in patients undergoing mitral valve surgery: The Swedish Multicentre Atrial Fibrillation Study (SWEDMAF). Eur Heart J 2007; 28: 2902-2908.

36. Chevalier P, Leizorovicz A, Maureira P, Carteaux JP, Corbineau H, Caus $\mathrm{T}$, et al. Left atrial radiofrequency ablation during mitral valve surgery: A prospective randomized multicentre study (SAFIR). Arch Cardiovasc Dis 2009; 102: 769-775.

37. de Lima GG, Kalil RA, Leiria TL, Hatem DM, Kruse CL, Abrahao $\mathrm{R}$, et al. Randomized study of surgery for patients with permanent atrial fibrillation as a result of mitral valve disease. Ann Thorac Surg 2004; 77: 2089-2094; discussion 2094-2095.

38. Deneke T, Khargi K, Grewe PH, Laczkovics A, von Dryander S, Lawo $\mathrm{T}$, et al. Efficacy of an additional Maze procedure using cooled-tip radiofrequency ablation in patients with chronic atrial fibrillation and mitral valve disease: A randomized, prospective trial. Eur Heart J 2002; 23: 558-566.

39. Schuetz A, Schulze CJ, Sarvanakis KK, Mair H, Plazer H, Kilger E, et al. Surgical treatment of permanent atrial fibrillation using microwave energy ablation: A prospective randomized clinical trial. Eur J Cardiothorac Surg 2003; 24: 475-480; discussion 480.

40. Gaita F, Riccardi R, Caponi D, Shah D, Garberoglio L, Vivalda L, et al. Linear cryoablation of the left atrium versus pulmonary vein cryoisolation in patients with permanent atrial fibrillation and valvular heart disease: Correlation of electroanatomic mapping and longterm clinical results. Circulation 2005; 111: 136-142.

41. Deneke T, Khargi K, Grewe PH, von Dryander S, Kuschkowitz F, Lawo T, et al. Left atrial versus bi-atrial maze operation using intraoperatively cooled-tip radiofrequency ablation in patients undergoing open-heart surgery: Safety and efficacy. J Am Coll Cardiol 2002; 39: $1644-1650$

42. Barnett SD, Ad N. Surgical ablation as treatment for the elimination of atrial fibrillation: A meta-analysis. J Thorac Cardiovasc Surg 2006; 131: $1029-1035$.

43. Schuessler RB, Kay MW, Melby SJ, Branham BH, Boineau JP, Damiano RJ Jr. Spatial and temporal stability of the dominant frequency of activation in human atrial fibrillation. $J$ Electrocardiol 2006; 39: S7-S12.

44. Navarrete A, Conte F, Moran M, Ali I, Milikan N. Ablation of atrial fibrillation at the time of cavotricuspid isthmus ablation in patients with atrial flutter without documented atrial fibrillation derives a better long-term benefit. J Cardiovasc Electrophysiol 2011; 22: 34-38.

45. Soni LK, Cedola SR, Cogan J, Jiang J, Yang J, Takayama H, et al. Right atrial lesions do not improve the efficacy of a complete left atrial lesion set in the surgical treatment of atrial fibrillation, but they do increase procedural morbidity. J Thorac Cardiovasc Surg 2013; 145: $356-361$; discussion $361-363$.

46. Krul SP, Driessen AH, van Boven WJ, Linnenbank AC, Geuzebroek GS, Jackman WM, et al. Thoracoscopic video-assisted pulmonary vein antrum isolation, ganglionated plexus ablation, and periprocedural confirmation of ablation lesions: First results of a hybrid surgical-electrophysiological approach for atrial fibrillation. Circ Arrhythm Electrophysiol 2011; 4: 262-270.

47. La Meir M, Gelsomino S, Lorusso R, Luca F, Pison L, Parise O, et al. The hybrid approach for the surgical treatment of lone atrial fibrillation: One-year results employing a monopolar radiofrequency source. J Cardiothorac Surg 2012; 7: 71.

48. La Meir M, Gelsomino S, Luca F, Pison L, Parise O, Colella A, et al. Minimally invasive surgical treatment of lone atrial fibrillation: Early results of hybrid versus standard minimally invasive approach employing radiofrequency sources. Int J Cardiol 2012 May 2, doi: 
10.1016/j.ijcard.2012.04.044.

49. Mahapatra S, LaPar DJ, Kamath S, Payne J, Bilchick KC, Mangrum $\mathrm{JM}$, et al. Initial experience of sequential surgical epicardial-catheter endocardial ablation for persistent and long-standing persistent atrial fibrillation with long-term follow-up. Ann Thorac Surg 2011; 91: $1890-1898$

50. Pison L, La Meir M, van Opstal J, Blaauw Y, Maessen J, Crijns HJ Hybrid thoracoscopic surgical and transvenous catheter ablation of atrial fibrillation. J Am Coll Cardiol 2012; 60: 54-61.

51. Muneretto C, Bisleri G, Bontempi L, Curnis A. Durable staged hybrid ablation with thoracoscopic and percutaneous approach for treatment of long-standing atrial fibrillation: A 30-month assessment with continuous monitoring. J Thorac Cardiovasc Surg 2012; 144: 1460-1465; discussion 1465.

52. Bisleri G, Rosati F, Bontempi L, Curnis A, Muneretto C. Hybrid approach for the treatment of long-standing persistent atrial fibrillation: Electrophysiological findings and clinical results. Eur J Cardiothorac Surg 2013 March 8, doi:10.1093/ejcts/ezt115.

53. Muneretto C, Bisleri G, Bontempi L, Cheema FH, Curnis A. Successful treatment of lone persistent atrial fibrillation by means of a hybrid thoracoscopic-transcatheter approach. Innovations (Phila) 2012; 7: 254-258.

54. He B, Lu Z, He W, Wu L, Cui B, Hu X, et al. Effects of ganglionated plexi ablation on ventricular electrophysiological properties in normal hearts and after acute myocardial ischemia. Int J Card 2012 October 2, doi:10.1016/j.ijcard.2012.09.067.
55. Sakamoto S, Schuessler RB, Lee AM, Aziz A, Lall SC, Damiano RJ Jr. Vagal denervation and reinnervation after ablation of ganglionated plexi. J Thorac Cardiovasc Surg 2010; 139: 444-452.

56. Scherlag BJ, Nakagawa H, Jackman WM, Yamanashi WS, Patterson E, Po S, et al. Electrical stimulation to identify neural elements on the heart: Their role in atrial fibrillation. J Interv Card Electrophysiol 2005; 13(Suppl 1): 37-42.

57. Katritsis D, Giazitzoglou E, Sougiannis D, Goumas N, Paxinos G, Camm AJ. Anatomic approach for ganglionic plexi ablation in patients with paroxysmal atrial fibrillation. Am J Cardiol 2008; 102: $330-334$.

58. Hirose M, Leatmanoratn Z, Laurita KR, Carlson MD. Partial vagal denervation increases vulnerability to vagally induced atrial fibrillation. J Cardiovasc Electrophysiol 2002; 13: 1272-1279.

59. Lo LW, Scherlag BJ, Chang HY, Lin YJ, Chen SA, Po SS. Paradoxical long-term proarrhythmic effects after ablating the "head station" ganglionated plexi of the vagal innervation to the heart. Heart Rhythm 2013; 10: 751-757.

60. Saint LL, Bailey MS, Prasad S, Guthrie TJ, Bell J, Moon MR, et al. Cox-Maze IV results for patients with lone atrial fibrillation versus concomitant mitral disease. Ann Thorac Surg 2012; 93: 789-794; discussion 794-795.

61. Damiano RJ Jr, Gaynor SL, Bailey M, Prasad S, Cox JL, Boineau JP, et al. The long-term outcome of patients with coronary disease and atrial fibrillation undergoing the cox maze procedure. J Thorac Cardiovasc Surg 2003; 126: 2016-2021. 